\title{
An Unusual Presentation of De Quervain's Disease
}

\author{
*James Bassett, Tim McBride and Richard Dias \\ Consultant Orthopaedic Hand \& Upper Limb Surgeon, UK
}

Submission: April 12, 2017; Published: April 17, 2017

*Corresponding author: James Bassett, Consultant Orthopaedic Hand \& Upper Limb Surgeon, UK, Email: Bertie.jb@googlemail.com

\begin{abstract}
De Quervain's tenosynovitis is a condition affecting individuals who perform repetitive activities using their hands. It has been found to affect women more than men with a relative risk as high as 8:1. A recent study has also found the black race as a risk factor. There is substantial variation of the first extensor compartment with different degrees of subcompartmentalisation and numbers of tendon slips.

This report describes a young lady in her teens with unusual symptoms relating to De Quervain's tenosynovitis with bruising tracking along the extensor aspect of the forearm in conjunction with the typical tenderness and a positive Finkelstein's test. In this case a single thickened tendon of APL was found with a bruised muscle belly tracking through De Quervain's tunnel as the likely cause for these abnormal symptoms.
\end{abstract}

This case highlights the importance of clinical findings to guide management, as investigations in this case including MRI scan were normal.

\section{Introduction}

De Quervain's tenosynovitis affects individuals who perform repetitive activities using their hands. It has been found to affect women more than men, with an odds ratio of 8:1. There is substantial variation of the first extensor compartment with different degrees of subcompartmentalisation and numbers of tendon slips.

\section{Case Report}

This is a case of a young lady referred by her GP with pain over the radial aspect of her non-dominant wrist with corresponding bruising along the radial aspect of the forearm up to the elbow. This became worse after using a keyboard or similar repetitive activities and was more noticeable at night. At the time of initial presentation she also complained of occasional pins and needles in the fingers. Her symptoms dated back to 2008 however she was first seen in clinic in 2011.

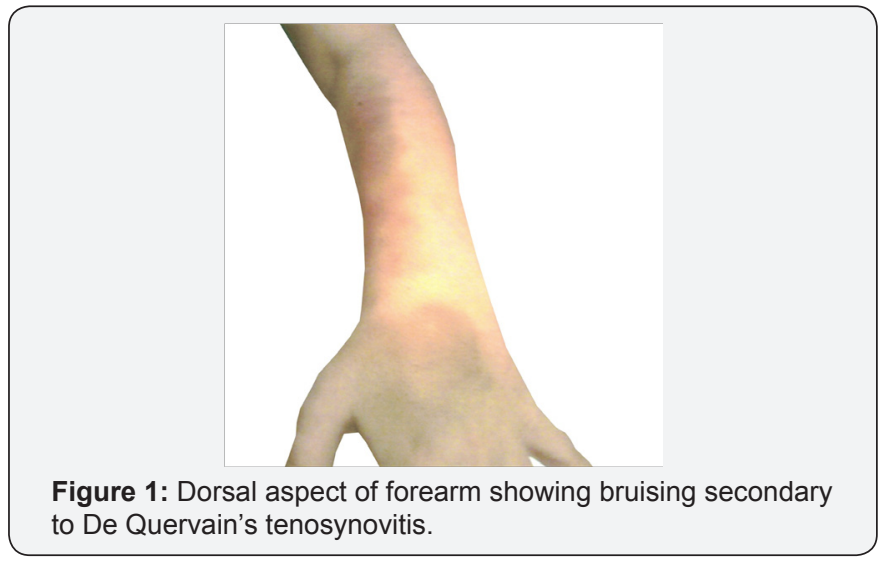

On initial examination the patient was found to have bruising tracking proximally along the radial aspect of the forearm up to the elbow. There was tenderness along the first extensor compartment at the wrist with a positive Finkelstein's test. The range of movement in all the joints was normal (Figures $1 \& 2$ ).

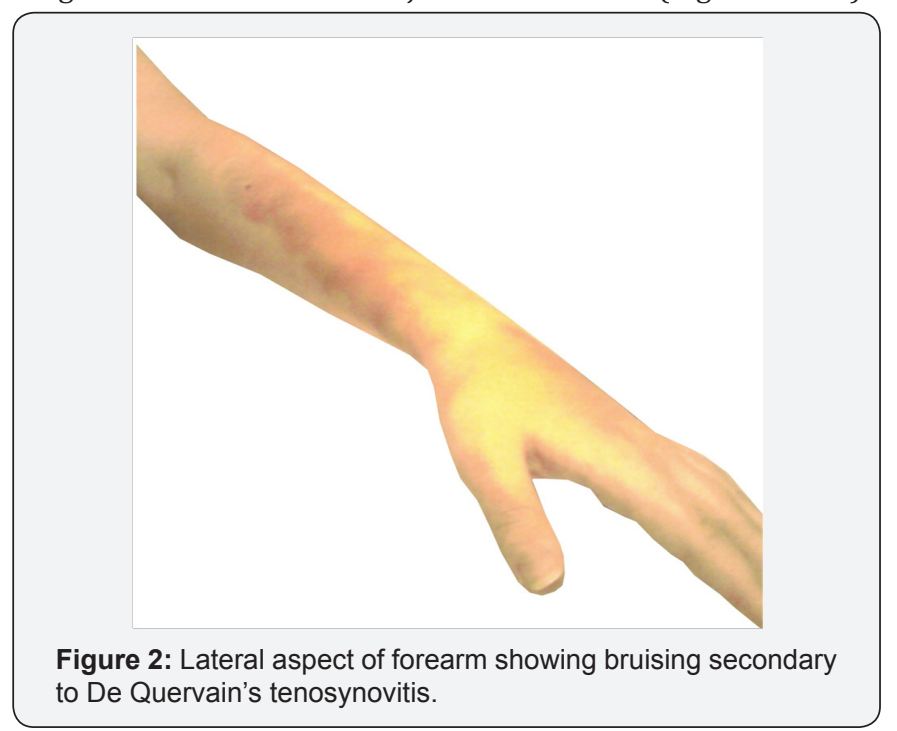

Due to the unusual presentation of what appeared to be De Quervain's Tenosynovitis and possible carpal tunnel, a MRI scan and nerve conduction studies were requested.

Nerve conduction studies and MRI of the left wrist were unremarkable but it is to be noted that patient was relatively asymptomatic at the time of scanning. There was some fluid around the intercarpal ligaments, and a Rheumatology consult 
was sought. A rheumatological screen was performed and found to be normal and it was thought the MRI findings were incidental.

The symptoms continued and a steroid injection to de Quervain's tunnel gave short-term relief on two separate occasions.

There were further intermittent episodes of bruising following a 'click' in de Quervain's tunnel. A repeat MRI during an episode of bruising was completed with findings consistent with the initial MRI in 2011. She was also seen by Haematology and Vascular Surgery to rule out any other causes of this bruising. All investigations were again normal.

In late 2013 a severe episode with significant bruising tracking up the radial aspect of the forearm prompted an urgent clinic review and a decision was made to explore and perform a de Quervain's release.

The tunnel itself was very tight and was released. The muscle belly of abductor pollicis longus (APL) was found to traverse the whole length of de Quervain's tunnel becoming tendinous only after exiting. The APL tendon was single and thickened with significant bruising of the muscle belly and surrounding structures. This was the cause of the symptoms of both De Quervain's tenosynovitis and extensive bruising.

At serial follow up there was no further bruising, clicking around the wrist or symptoms of de Quervain's tenosynovitis. The patient is currently asymptomatic and is continuing her education at University.

\section{Discussion}

De Quervain's usually has a classical presentation, however common conditions are occasionally a diagnostic conundrum. On searching the literature, there have been no descriptions of the muscle belly of APL stretching into De Quervain's tunnel, nor have there been cases of De Quervain's with bruising tracking up the forearm. This case illustrates an unusual combination of symptoms for de Quervain's disease, the importance of clinical assessment and not relying solely on radiological findings.

The first extensor compartment is usually made up of abductor pollicis longus (APL) and extensor pollicis brevis
(EPB) tendons. Significant anatomical variation occurs in the first extensor compartment with differences in both the tendon sheath and tendon numbers. Hiranuma described 4 types of De Quervain's disease (Type I - a single tendon sheath encompassing APL and EPB, Type II - complete separation of tendon sheaths of the APL and EPB, Type III - incomplete separation of tendon sheaths, Type IV - absence of EPB tendon). Motoura (2010) [1] found incidence was highest in type I and reduces with type (63.4\% type I, $23.2 \%$ type II, $8.9 \%$ type III, $4.5 \%$ type IV). Jackson (1986) [2] found $40 \%$ of patients had subcompartmentalisation (Type II/III) of the first extensor compartment 18\% (Type III) of these being incomplete. Jackson (1986) also found that $57 \%$ of patients had 2 APL tendons and 1 EPB tendon [3]. The incidence of multiple APL tendons is high with some series reporting more than $50 \%$ of patients having three or more tendons [4]. The incidence of multiple tendon slips of EPB on the other hand is low with only $2-10 \%$ having two or more tendons.

evaluation of multiple joints including the knee, shoulder, wrist, elbow, and ankle (Figure 3). This device probably has the greatest utility when it comes to research efforts. Both observation as well as procurement of tissue is now

Possible with a minimal amount of difficulty, assuming the individual has been trained in the use of the device. That alone should provide the impetus for training programs to adopt this technique.

\section{References}

1. Motoura H, Shiozaki K, Kawasaki K (2010) Anatomical variations in the tendon sheath of the first compartment. Anat Sci Int 85(3): 145-151.

2. Jackson WT, Viegas SF, Coon TM, Stimpson KD, Frogameni AD, Simpson JM (1986) Anatomical variations in the first extensor compartment of the wrist: a clinical and anatomical study. J Bone Joint Surg Am 68(6): 923-926.

3. Hiranuma A, Houjo H, Sakaguchi S (1972) De Quervain's tenosynovitis and anatomical variation of first extensor compartment. Orthop Surg 23: 1186-1188.

4. Choi SJ, Ahn JH, Lee YJ, Ryu DS, Lee JH, et al. (2011) de Quervain Disease: US Identification of Anatomic Variations in the First Extensor Compartment with an Emphasis on Subcompartmentalization. Radiology 260(2): 480-486.
This work is licensed under Creative

Commons Attribution 4.0 License

DOI: $10.19080 /$ OROAJ.2017.06.555683
Your next submission with Juniper Publishers will reach you the below assets

- Quality Editorial service

- Swift Peer Review

- Reprints availability

- E-prints Service

- Manuscript Podcast for convenient understanding

- Global attainment for your research

- Manuscript accessibility in different formats

( Pdf, E-pub, Full Text, Audio)

- Unceasing customer service

Track the below URL for one-step submission https://juniperpublishers.com/online-submission.php 